\title{
Telecommunications Companies in Bulgaria: Challenges and Opportunities in a Social Isolation Environment due to COVID-19
}

\author{
Nadezhda Miteva \\ The Saint Kliment Ochridsky Sofia University, Sofia, Bulgaria \\ Email: hopeace@abv.bg,nmiteva1@uni-sofia.bg
}

How to cite this paper: Miteva, N. (2020). Telecommunications Companies in Bulgaria: Challenges and Opportunities in a Social Isolation Environment due to COVID-19. Open Journal of Business and Management, 8, 2729-2739.

https://doi.org/10.4236/ojbm.2020.86169

Received: September 18, 2020

Accepted: November 22, 2020

Published: November 25, 2020

Copyright ( 2020 by author(s) and Scientific Research Publishing Inc. This work is licensed under the Creative Commons Attribution International License (CC BY 4.0).

http://creativecommons.org/licenses/by/4.0/

\begin{abstract}
The period of lockdown due to the new coronavirus spreading convinces the public all over the world that the activity and the working of telecommunication companies are of crucial importance for the normal functioning of the economy and the society as a whole. This paper examines the activities and politics of the leading Bulgarian mobile network operators in an unprecedented stressful situation and under the increased supervision of the regulatory body during the state of emergency imposed by the government (13 March-13 May 2020). The methodology relevant to this purpose consists of descriptive and analytical tools, including interviews with representatives of telecommunications companies and Communications Regulation Commission of the Republic of Bulgaria. The pandemic situation brings network operators higher revenues, a rise in consumption of digital services and the opportunity to convince the public of their growing corporate and social responsibility. Along with the privileges, the COVID-19 crisis burdens telecommunications companies with the responsibility to maintain their networks and operations in an environment of unprecedented overload, as well as managing and mitigating the stress in society caused by the imposed deep and sudden changes. This positive image of Bulgarian telcos can be threatened by the intention of politicians to use mobile traffic data for tracking.
\end{abstract}

\section{Keywords}

Mobile Network Operators, COVID-19, State of Emergency, Digital Services, Social Responsibility, Tracking

\section{Introduction and Research Design}

The spread of a new coronavirus strain and the COVID-19 disease, which it 
causes among humans, leads to cumulative border closures for many months in various parts of the world. The unprecedented decision of many governments, including the government of the Republic of Bulgaria (Council of Ministers of the Republic of Bulgaria, Emergency Meeting's Decisions, March 12, 2020), tests the capacity for balanced decision-making and the crisis response systems as well as every segment of the economic and social life, which is most evident in digital infrastructures and connectivity in each and every country. For many business sectors (e.g. tourism, restaurant services, retail trade and commerce, transport and logistics, media, entertainment industry and film production), the period of forcefully imposed anti-epidemic measures has an adverse effect, which results in temporary or permanent termination of activity, furloughs and lay-offs of employees, financial losses, reorganization of supply and distribution chains, filings for bankruptcy (United Nations Industrial Development Organization, 2020).

However, for telecommunications industry, the challenges it faces have the opposite impact. From the very first days of the social isolation period, the mobile network operators and the internet providers, based in the affected regions of the world, have been facing peak consumption, leading to transmission networks capacity overloads and the respective services and service units. Their ability to withstand in this situation was crucial not only for providing a good connectivity to all their subscribers, but to secure smooth functioning of the education system, of the state administration, all digital services and work from home of a huge majority of people ("COVID-19 Industry Updates and Guidance", n.d.).

The author's thesis is that, in addition to responsibilities, the pandemic situation brings to the network operators higher revenues, in the form of new and/or more favorable contracts with subscribers, a rise in consumption of digital services, and the opportunity to convince the public of their growing corporate and social responsibility. The aim of this study is to research the politics of the Bulgarian telecommunications companies in an unprecedented stressful situation and under the increased supervision of the regulatory body. The object of the research is the activity and the actions of the three leading mobile network operators in Bulgaria (A1, Telenor Bulgaria and Vivacom) during the state of emergency due to COVID-19 (13 March-13 May 2020). The subjects of the research are the management decisions of the telecoms' management teams in order to cope with the network overload (never seen before) and the growing consumption of services; the measures taken to provide relevant physical and cyber security of their employees as well as their clients; the marketing strategies for retaining existing and attracting new clients; the promotion of new digital products and services; show of social solidarity and support.

\section{Methods and Data Collection}

The research methods are relevant to the research aim. They also take into account the fact that the research period coincides with the situation where the research object/event deploys and all of us (including the author) we are witnesses 
to the studied phenomenon. This is the reason why the research methods are mixed and include (participant) observation, description, data collection and secondary data analysis. Among the main sources of information are United Nations (UNDP, UNICEF, UNIDO) and World Bank reports, professional and scientific publications, corporate, governmental and non-governmental websites, the telecommunications companies and Communications Regulation Commission-the regulatory body in the field of telecommunications and the postal services in Bulgaria. As the financial results for the current year are not available yet, some of the conclusions are based on preliminary data and indirect estimates (e.g. number of new users and subscriptions, amount of the donations etc.).

\section{Results}

During the two-month period of social isolation (March 13-May 13) the Bulgarian mobile network operators adapted quickly to unexpected changes in public and economic life while being quite flexible. Adaptation to the new conditions begins literally on the next day after the declaration of a state of emergency in the country. It occurs in several directions: 1 ) measures to guarantee the security of employees and customers, including by encouraging customers to use existing digital services as well as newly developed ones; 2 ) measures, aimed at providing consumers with new opportunities for full-blown communication and entertainment while abiding by requirements for social isolation; 3 ) measures to enhance cyber security; 4) donor's and sponsor's campaigns to engage consumers.

During the state of emergency period the telecommunication companies in Bulgaria operate under the intensified control of the Communications Regulation Commission (CRC), at the same time making use of the renewed legal opportunity for acquiring mobile data for mass and uncontrolled monitoring.

\subsection{Anti-Virus Measures and Digital Services}

Non-cash payments and online customer services are not a new opportunity for Bulgarian business, however after March 13, 2020 it has been booming. It is interesting to note that the day before the state of emergency was imposed, A1 published on its corporate website information that the company is ready to adopt this measure ("A1 Is Ready to Serve Its Clients Online in Order to Prevent the Spreading of COVID-19", 2020). The company insists on offering its customers purchasing services through a "Video Assistant" (consulting by video call to an employee). Telecommunications companies take advantage of the imposed period of forced social isolation to promote online purchases of devices, gadgets and accessories by using mobile applications as well as discounts, gifts and incentives. Besides, the period is favorable for promoting their own mobile platforms for various payment transactions (A1 Wallet, Pay by Vivacom).

The efforts made by the mobile networks operators have been paying off. Telenor reports doubling the number of purchases from the company's E-shop (Electronic shop) and 59\% rise in payments through the MyTelenor mobile ap- 
plication in April, compared to February ("Telenor's Network Withstood the Challenges and Was Sertified Best In Test in Bulgaria Again”, 2020). A1 reports $300 \%$ increase in video store calls and about $200 \%$ increase in users who connect with company employees via chat and social networks ("A1 Donates 1 leva from Every Online Payment to the Ministry of Health", 2020). Maintaining the upward trend in online customer service after the end of the state of emergency is paired with additional incentives, as well as with the level of security and protection of users' data and users' payments.

\subsection{Social Solidarity and Online Security in Times of Isolation}

Providing additional opportunities for communication, connectivity, entertainment and training for consumers during the forced imposed isolation is a unifying policy for the three leading mobile network operators in Bulgaria. The basic offer is a free package comprising: supplementary minutes for phone calls, mobile internet and television channels for all clients for the period of the state of emergency. Consumers are able to activate it easily-by using a mobile app or by sending a sms.

The package offered by Vivacom seems to be most-differentiated in order to meet the needs of the various groups of clients. The company introduces various insentives for children and adults, school children, disadvantaged people, people with disbilities, small and medium enterprises businesses, people with active sports life and other categories (\#IstayAtHome. 2020).

All mobile network operators, in cooperation with the National Operational Headquarters, maintain the free ViruSafe mobile application for daily detection of clinical symptoms and for tracking down sick patients. Besides, the three companies strive to raise awareness among their users by publishing useful articles on current topics, such as "How to disinfect your phone", "How to recognize fake news", "Is 5G harmful” (Karabelyov \& Karapenchev, 2020).

To facilitate business customers, digital services for managing work from home have been developed, for example, Virtual telephone exchange for remote customer service, mobile app for exchange of invoices and documents Paper online, mobile app for remote orders and approval of leave Otpuski.com etc. ("Telenor Extends the Grace Period for Business Services", 2020). Vivacom offers access to the cloud service VivaCloud (\#StayHome. bg, 2020) to build its own virtual data center at preferential prices by the end of May 2020.

Attracting more internet consumers often serves the purposes of online vendors (including mobile network operators), however it has some perils too. Telenor offers a series of educational videos about the dangers in online space and how to protect yourself. The target audiences of these videos are children and teenagers. It is offered completely free of charge for the imposed learning from home period ("Telenor Offers Video Editor on Online Security", 2020).

In April A1 developed and offered an app for prevention and fighting telephone fraud. It was the first of its kind in Bulgaria. A1 Guard can be used free of 
charge by clients of all three mobile network operators as well as A1 fixed (land) telephone lines clients ("Technologies against Telephone Fraudsters", 2020). Its release is in line with the warnings of the Ministry of Interior that telephone fraudsters have become even more active in times of social isolation (Ministry of Interior of the Republic of Bulgaria, 2020).

\subsection{Shared Responsibility during the Crisis}

Telecommunication companies in Bulgaria have developed large-scale donations activity during the state of emergency (13 March-13 May 2020). Donation campaigns are organized in two directions-direct assistance to health authorities and hospitals to effectively deal with coronavirus infection and support for schools and students in adapting to learning from home.

The support for the education system is being provided in various waysVivacom donates tablets to the Ministry of Education and Science ("Vivacom Donates 500 Tablets for Home Learning", 2020); computers for schools in remote areas in the countryside as well as family-type accommodation centres ("Telenor's Network Withstood the Challenges and Was Sertified Best In Test in Bulgaria Again", 2020); providing reliable high-speed internet connections to secure smooth-running educational process with pupils attending classes from home. Also telecommunication companies report that they have provided substantial funding to the healthcare system during the state of emergency. Reported are donations of medical face masks ("Telenor and PPF Group Donate Professional Face Masks at about 500,000 leva for Bulgarian Hospitals", 2020) and consumables, smartphones for hospitals staff ("Telenor Donated 50 Smartphones CAT S52 to the Military Hospital, Pirogov Hospital and the Sofia Emergency Center", 2020), respirators (“A1 Donated Five Respirators to Alexandrovska Hospital", 2020), thermo cameras for measuring body temperature ("VIVACOM Installed Termo Cameras in Pleven and Blagoevgrad Municipalities", 2020), disinfections robot ("VIVACOM Supports the Fight against COVID-19 by Donating 300,000 leva to Bulgarian Hospitals", 2020). The total amount of the announced donations from the telecommunication companies for combating COVID-19 during the emergency state period is BGN 1,320,000 (about €677,000).

An interesting detail from the PR strategy of telecoms is the drive to attract consumers as participants in donations fundraising. A1 declares that it transfers to the donation account of the Ministry of Health 1 BGN from each invoice, paid online. Same applies to $1 \%$ of each payment made by using the digital platform A1Wallet ("A1 Donates 1 leva from Every Online Payment to the Ministry of Health", 2020). Vivacom mobilizes its customers by donating the first monthly fees from all new subscription contracts concluded in April and the doubled monthly fees for each online service launched during the same month ("VIVACOM Supports the Fight against COVID-19 by Donating 300,000 leva to Bulgarian Hospitals", 2020). 
The amount of donated funds is an indirect indicator of the increase in revenues of telecommunications companies during the period of imposed social isolation in Bulgaria. The set of declared measures, put in place, to encourage consumers to stay at home and live in safety, while having access to connectivity and opportunities for work, jobs, learning and entertainment, resulted in sales increase and rise of newly activated services. It is fair and reasonable to return some of the collected money to the community. The donated funds, raised with the active participation of consumers, turn out to be a two-fold investment. On the one hand, this is an investment in the protection of life and health of the people and in the development of the digital society, and on the other hand-it is an investment in higher trust in the companies and in their image of responsible entities, which show solidarity with the imposed changes in public life. This image is reaffirmed by the monitoring of the working and the activities of the mobile networks operators, executed by the Communications Regulation Commission (CRC) during the state of emergency.

\subsection{Monitoring the Working of the Mobile Networks during the State of Emergency (13 March-13 May)}

The state of emergency in the country, imposed on 13 March, forces a significant number of people to work and study from home. This puts enormous stress on the transmission infrastructure of mobile network operators. A sharp rise in phone calls ( $32 \%$ up, compared to the average values for the previous Sundays) is registered on $8 \mathrm{March}$, when the news of the first infected people are confirmed. Telenor reports a historic peak in mobile data traffic on March 23, when a pass regime for travel in the country is introduced and check points are set up around every big city (Kirilova, 2020).

The mail services and electronic communications regulatory body-The Communications Regulation Commission (CRC) is anxiously monitoring the operation of the transmission networks and appeals for prudent use and prioritization of traffic in order to avoid a breakdown (Communications Regulation Commission, 2020c).

During the state of emergency, the Commission is closely monitoring the operation of mobile networks and the quality of services for end-users. By the beginning of April, is reported an average growth by $46 \%$ of telephone calls via mobile networks (11\% growth in fixed networks) and 19\% growth in data traffic ( $41 \%$ in fixed networks). Table 1 and Figure 1 show the dynamics in data traffic and voice services consumption during the state of emergency (13 March-13 May 2020).

The peak in phone calls and the usage of Internet over mobile and fixed networks till the end of March is clearly visible. This is explained with the imposed forced social isolation, the suspension of almost all activities and the attempts to carry them out remotely (for example, work and study from home, online shopping and paying bills online, medical consultations by phone etc). High levels of 
stress in people due to sudden changes in their lives, as well as the ban on traveling in the country without a valid reason also contribute to the mobile and fixed networks workload.

Stabilized consumption in the first half of April gradually begins to decline and, with the elimination of most anti-epidemic measures, in May the indicators remain higher, however, close to the values before March 13. One exception is the data traffic via fixed networks, which in Bulgaria is the preferred way to use the internet (Communications Regulation Commission, 2019).

The pressure on the transmission networks of mobile operators in Bulgaria during the state of emergency can be considered a serious stress test in a real situation. The CRC (regulatory body) assessment is that the telecommunication companies manage to cope with the challenge, preventing a breakdown, interruption of services, and not avoiding significant reduction of speed and/or network coverage.

Telenor admits that during the state of emergency they had to strengthen their network in over 100 points throughout the country (Kirilova, 2020). The Vivacom team attributes the successful handling of the challenge to the investments made during the previous years as well as to the opportunity to cross-use part of the spectrum and capacity in $2 \mathrm{G}, 3 \mathrm{G}$ and $4 \mathrm{G}$, depending on their workload ("Vivacom's Network Works with No Difficulties in the Condition of Overload", 2020).

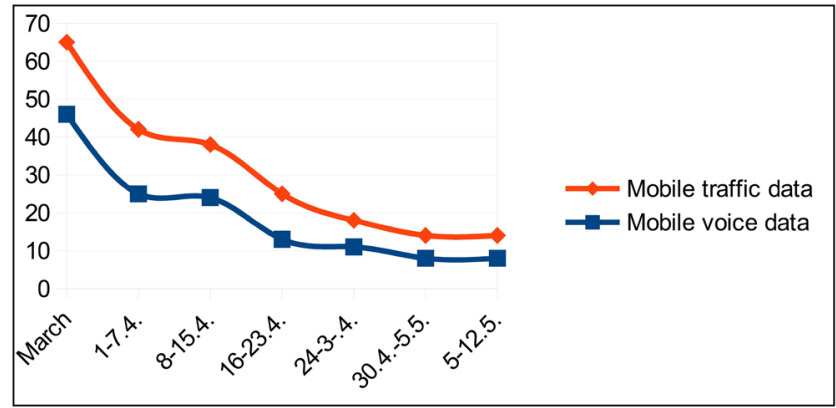

Figure 1. Growth of consumption using mobile networks (\%), compared to the week before the state of emergency to be imposed. Source: Communications Regulation Commission, 2020e.

Table 1. Growth of consumption using fixed and mobile networks (\%), compared to the standard week before the state of emergency to be imposed.

\begin{tabular}{cccccccc}
\hline & 13-31 March & $1-7$ April & 8-15 April & 16-23 April & 24-30 April & 30 April-5 May & 5-12 May \\
\hline Mobile voice data & 46 & 25 & 24 & 13 & 11 & 8 & 8 \\
Fixed voice data & 19 & 17 & 14 & 12 & 7 & 3 & 6 \\
Mobile traffic data & 11 & 19 & 13 & 8 & 23 & 1,5 & 19 \\
Fixed traffic data & 41 & 34 & 30 & 23 & & 17 \\
\hline
\end{tabular}

Source: Communications Regulation Commission, 2020e. 
The social isolation in the context of a declared pandemic exacerbates the natural fears of many people about their lives and health (Raycheva et al., 2020). It is a fertile ground for conspiracy theories to emerge and flourish. In April, the Communications Regulation Commission (CRC) was forced to reassure the public that in Bulgaria there are no existing $5 \mathrm{G}$ networks in operation (Communications Regulation Commission, 2020d). The CRC published on its website the Position of the Body of European Regulators for Electronic Communications. It presents the high standards for safety and protection of public health during the construction and during the operation of 5G mobile networks ("Position of the Body of European Regulators for Electronic Communications On the 5G Networks Development and the Public Health Protection", Communications Regulation Commission, 2020b).

\section{Discussion and Conclusion}

The declared pandemic and the accompanying restrictive measures convince the public that the activity and the working of telecommunication companies are of crucial importance for the normal functioning of the economy and the society as a whole.

One of the most remarkable things during the state of emergency in Bulgaria is the change in attitude towards mobile network operators consumers. All those additional opportunities for free of charge phone calls, work and employment, entertainment and learning are aimed to persuade the user that he is "the important one" for the company and for the society. Mobile network operators use the \#Stayhome! Savelife slogan to encourage their customers to try unfamiliar ways of doing everyday activities that they are unlikely to resort to under normal circumstances. No doubt, it brings revenue to telecoms, but it also serves the digital literacy of the individual consumer and the development of the digital society as a whole.

Donation campaigns, which have raised impressive sums in support of the healthcare system, are based on the principle of shared responsibility. Campaign organizers attempt to cultivate and stimulate in their consumers qualities such as trust, loyalty, commitment and to create communities which share similar values. The consumers are now elevated to the status of being partners, instead of clients. They are the focus of attention. Their participation is important both for the future of company and for the community as well.

Although this research is limited in time and space, the results are in tune with the main perspectives of the World Bank Group report on the impact of COVID-19: in short-terms, telecommunication sector will derive benefits from the imposed restrictions and probably will continue to grow due to the increased demand of digital services. However, it may encounter some difficulties because of the general reduced economic activity in mid-terms (International Finance Corporation. World Bank Group, 2020).

The period of internal social isolation enables mobile network operators to 
convince the society of their significance, responsibility and solidarity. The efforts made by the telecoms are a chance to maintain the upward trend in the development of the mobile services market, a trend registered in 2018 and 2019 after a 10-year decline (Communications Regulation Commission, 2019, 2020a) However, the intention of politicians to use traffic data for tracking, followed by subsequent judicial control, can undermine the hard-won trust of consumers in mobile network operators. In 2015, the Constitutional Court (Judgment No 2/12.03.2015 in Case No 8/2014) protected the rights of citizens from such an encroachment. Now, a new decision by the same court is expected again ("The Constitutional Court Precludes the Examination of the Substance in Case No $4 / 2020 ", 2020)$. This time is in a changed environment-it will be taken against the background of growing disrespect for human rights by various governments around the world, disguised as caring for people's lives and health.

The above-mentioned challenges only emphasize the enormous responsibility, which lays on the mobile network operators, not only for maintaining connectivity in a "shut off" state, but also for managing and mitigating the stress in society caused by the imposed deep and sudden changes that occur.

\section{Acknowledgements}

The research has been developed within the framework of the EC COST Action CA16226 of the European Commission: Indoor Living Space Improvement. Smart Habitat for the Elderly (SHELD-ON), supported by the research project KP-06-COST/5-18/06/2019 and the Programme Young Scientists and Post Docs of the Bulgarian Ministry of Education and Science.

\section{Conflicts of Interest}

The author declares no conflicts of interest regarding the publication of this paper.

\section{References}

\#IstayAtHome. (2020). Vivacom Donates the First Monthly Fees for New Services in April to Combat COVID-19. Vivacom Bulgaria. https://www.vivacom.bg/bg/home

(2020). A1 Is Ready to Serve Its Clients Online in Order to Prevent the Spreading of COVID-19. A1 Bulgaria. (In Bulgarian)

https://www.a1.bg/medien-tsentar-informatsia-za-mediite/mc/index/ma/view/infobloc k_id/2722

(2020). Technologies against Telephone Fraudsters. Investor.bg. (In Bulgarian) https://www.investor.bg/telekomunikacii/457/a/tehnologiite-v-borba-s-telefonnite-izm amnici-301664

(2020). Telenor and PPF Group Donate Professional Face Masks at about 500,000 Leva for Bulgarian Hospitals. Telenor.bg. https://www.telenor.bg/bg/news

(2020). Telenor Donated 50 Smartphones CAT S52 to the Military Hospital, Pirogov Hospital and the Sofia Emergency Center. Telenor.bg. (In Bulgarian) 
https://www.telenor.bg/bg/news

(2020). Telenor Extends the Grace Period for Business Services. Telenor.bg. (In Bulgarian) https://www.telenor.bg/bg/news

(2020). Telenor Offers Video Editor on Online Security. Telenor.bg. (In Bulgarian) https://www.telenor.bg/bg/news

(2020). Vivacom Donates 500 Tablets for Home Learning. Mediapool.bg. (In Bulgarian) https://www.mediapool.bg/vivakom-daryava-500-tableta-za-distantsionno-obuchenienews304795.html

(2020). VIVACOM Installed Termo Cameras in Pleven Municipality and Blagoevgrad Municipality. Vivacom Bulgaria. (In Bulgarian) https://www.vivacom.bg/bg/home

(2020). VIVACOM Supports the Fight against COVID-19 by Donating 300,000 Leva to Bulgarian Hospitals. Vivacom Bulgaria. (In Bulgarian)

https://www.vivacom.bg/bg/home

(2020). Vivacom's Network Works with No Difficulties in the Condition of Overloads. Vivacom Bulgaria. (In Bulgarian) https://www.vivacom.bg/bg/home

(2020). A1 Donated Five Respirators to Alexandrovska Hospital. A1 Bulgaria. (In Bulgarian)

https://www.a1.bg/medien-tsentar-informatsia-za-mediite/mc/index/ma/view/infobloc k_id/2726

(2020). A1 Donates 1 Leva from Every Online Payment to the Ministry of Health. A1 Bulgaria. (In Bulgarian)

https://www.a1.bg/medien-tsentar-informatsia-za-mediite/mc/index/ma/view/infobloc k_id/2731

(n.d.). COVID-19. Industry Updates and Guidance. GSMA. https://www.gsma.com/newsroom/covid-19-industry-updates-and-guidance

(n.d.). Telenor's Network Withstood the Challenges and Was Sertified Best in Test in Bulgaria Again. Telenor.bg. (In Bulgarian) https://www.telenor.bg/bg/news

Communications Regulation Commission (2019). Electronic Communications Market State and Development (pp. 27-28). Report 2018. (In Bulgarian)

Communications Regulation Commission (2020a). Electronic Communications Market State and Development. Annual Report 2019. Crc.bg. (In Bulgarian) https://crc.bg/files/Annual_Report_CRC_2019.pdf

Communications Regulation Commission (2020b). Position of the Body of European Regulators for Electronic Communications on the $5 G$ Networks Development and the Public Health Protection. Crc.bg. (In Bulgarian)

https://crc.bg/bg/novini/1313/poziciq-na-organa-na-evropejskite-regulatori-v-oblasttana-elektronnite-syobshteniq-otnosno-razgryshtaneto-na-5-g-mrezhi-i-opazvane-na-ob shtestvenoto-zdrave

Communications Regulation Commission (2020c). The Commission Recommends That Users Must Comply Their Needs with the Current Internet Traffic Tendencies. Crc.bg. (In Bulgarian) https://crc.bg/bg/novini/1304/komisiqta-za-regulirane-na-syobshteniqta-preporychvana-potrebitelite-da-se-syobrazqt-s-tendenciite-v-internet-trafika

Communications Regulation Commission (2020d). The Commission States That There Is No $5 G$ Network in Operation in Bulgaria. Crc.bg. (In Bulgarian)

https://crc.bg/bg/novini/1308/krs-uvedomqva-che-nqma-raboteshti-5-g-mrezhi-na-ter itoriqta-na-stranata 
Communications Regulation Commission (2020e). The Condition of the Networks Is Under the Increased Monitoring of the Commission Since the Beginning of the State of Emergency. Crc.bg. (In Bulgarian)

https://crc.bg/bg/novini/1316/komisiqta-za-regulirane-na-syobshteniqta-prodylzhavanabljudenieto-vyrhu-mobilnite-mrezhi-i-dejnostta-na-licenziranite-poshtenski-operatori

Constitutional Court of the Republic of Bulgaria (2020). The Constitutional Court Precludes the Examination of the Substance in Case No 4/2020. Const. Court. Magazines. E-Reports. http://www.constcourt.bg/bg/Blog/Display/870?type $=1$

Constitutional Court of the Republic of Bulgaria. Annual Book 2015. Judgment No 2/12.03.2015 in Case No 8/2014 (pp. 27-57).

Council of Ministers of the Republic of Bulgaria (2020). Emergency Meeting's Decisions. (In Bulgarian) http://www.Gov.bg https://www.gov.bg/bg/prestsentar/zasedaniya-na-ms/dneven-red-na-izvanrednoto-zas edanie-na-ministerskiya-savet-na-12-03-2020-g

International Finance Corporation. World Bank Group (2020). COVID-19's Impact on the Global Telecommunication Industry.

https://www.ifc.org/wps/wcm/connect/1d490aec-4d57-4cbf-82b3-d6842eecd9b2/IFC-C ovid19-Telecommunications_final_web_2.pdf?MOD=AJPERES\&CVID=n9nxogP

Karabelyov, S., \& Karapenchev, Y. (2020). How to Recognize Falls News? How to Disinfect Your Smartphone? Is $5 G$ Harmful? A1 Bulgaria, Blog Post. (In Bulgarian) https://blog.a1.bg/category

Kirilova, E. (2020). Telenor: It Is Quite Early to Talk about 5 G Network in Bulgaria. Investor. (In Bulgarian)

https://www.investor.bg/telekomunikacii/457/a/telenor-rano-e-da-govorim-za-5g-mrej a-v-bylgariia-304675

Ministry of Interior of the Republic of Bulgaria (2020). A Campaign Preventing Citizens From COVID-19 Related Telephone Frauds Is In Progress [Video] (In Bulgarian).

Raycheva, L., Neli, V., Nadezhda, M., \& Mariyan, T. (2020). Impacts of Virtual Communication during Social Isolation of Covid'19. Human Systems Engineering and Design (IHSED 2020): Future Trends and Applications, Pula, 22-24 September 2020, 63-68. https://doi.org/10.1007/978-3-030-58282-1

United Nations Industrial Development Organization (2020). Coronavirus: The Economic Impact Report.

https://www.unido.org/stories/coronavirus-economic-impact-10-july-2020 